\title{
Nursing Workloads and Psychological Empowerment in Hospitals: Structural Equations Modeling
}

\author{
Parvin Ebrahimi ${ }^{1}$, Zainab Malmoon ${ }^{2 *}$, Rouhollah Zaboli \\ ${ }^{1}$ Health Management and Economics Research Centre, Iran University of Medical Sciences, Tehran, Iran \\ ${ }^{2}$ Department of Health Services Administration, School of Health Management and Information Sciences, Iran \\ University of Medical Sciences, Tehran, Iran \\ ${ }^{3}$ Department of Health Administration, Faculty of Health, Baqiyatallah University of Medical Sciences, Tehran, Iran
}

*Corresponding Author: Zainab Malmoon, Ph.D., Candidate, Department of Health Services Administration, School of Health Management and Information Sciences, Iran University of Medical Sciences, No 6, Rashid Yasemi St., Valie-Asr Ave., Tehran, Iran. Tel: +989122351067, Fax: +982188883334, Email: zemalmoon@gmail.com

Received June 10, 2017; Accepted July 30, 2017; Online Published August 12, 2017

\begin{abstract}
Background: The high workload of nurses in hospitals has been identified as a patient safety and worker stress problem. Psychological empowerment is a motivational concept demonstrated in four dimensions: meaning, competence, selfdetermination, and impact.

Objective: This study investigated the relationship between nurses' workloads and psychological empowerment using structural equations modeling (SEM).

Methods: This descriptive correlation study was conducted using SEM. The study was conducted at 17 public hospitals affiliated with Iran University of Medical Sciences (IUMS) in the city of Tehran. The population study was nurses employed in critical care departments. Two questionnaires were used to gather data: the NASA and the Psychological Empowerment Questionnaires. Differences in categorical variables were analyzed using one-way analysis of variance (ANOVA). Confirmatory factor analyses were used to confirm the relationships between latent variables and indicator variables; SEM was used to find the direct and indirect effects of nurse's workload on psychological empowerment. Data analyses were performed using SPSS 18, and all models were tested in LISREL 8.8.
\end{abstract}

Results: Correlations among indicators of nurse's workload showed that highest correlations were performances (0.61), and the highest correlations among psychological empowerment were competence (0.03). The overall correlations among nursing workloads and psychological empowerment were 0.74 . The proposed structural model fit was acceptable $(\chi 2=$ 525.5, $d f=89$, RMSEA = 0.13, GFI = 0.91).

Conclusion: Increasing the workload of nurses in hospitals will better engage the nurses and allow them to face new problems they encounter in their jobs.

Keywords: Workload, Nurses, Power, Hospitals

\section{Background}

The efficiency and effectiveness of health services depend on nurses as an important part of the healthcare system. As a main human resource in hospital organizations, nurses play a significant role in the success and promotion of patient health; health organizations cannot be successful without efficient nurses. Due to the high rate of patient referrals to hospitals, workload is a challenge faced by nursing management. ${ }^{1}$

Nursing in intensive care units (ICUs) is characterized by high complexity care and a greater demand for technical and scientific competence; immediate decision-making and the adoption of safe behaviors are directly related to the morbidity and mortality of patients. ${ }^{2}$ Although the high workload of nurses in ICUs has been identified as a major problem, little attention has been given this issue. ${ }^{3}$

The different aspects of a nurse's workload must be clarified so that the workload can be better managed and the satisfaction of critical care nurses in their workload increased. ${ }^{4}$ From the point of view of nurses, the main barriers to the relationship between patients and nurses are the lack of nurses, lack of sufficient time, and lack of patient awareness. ${ }^{5}$ The heavy workload of a hospital nurses is a major difficulty for hospitals. Evidence has shown that adverse patient outcomes are associated with some aspects of a nurse's workload. ${ }^{6-8}$

The results of this study showed that different methods, such as patient-based and operator-based workload, can be used to measure the workload of ICU nurses. The NASA Task Load Index (TLX) is the best questionnaire

Copyright $(2017$ The Author(s). This is an open-access article distributed under the terms of the Creative Commons Attribution License (http:// creativecommons.org/licenses/by/4.0), which permits unrestricted use, distribution, and reproduction in any medium, provided the original work is properly cited. 
to measure workload; NASA TLX can also be used in healthcare settings. ${ }^{9}$ To date, no study has pointed out the positive effects of workload on nurses. Those nurses who have a heavier workload have more learning opportunities and thus become more and more empowered. Assessing the workload is trying to predict the time and skills needed to dispense nursing care to clients/patients. ${ }^{7-9}$

Staff shortages in nursing cause burnout among nurses, high employee turnover, and poor service quality. Psychological empowerment is defined as a person's experience of intrinsic motivation that forms the perspective of the individual employee. ${ }^{10}$ According to Spreitzer, the process of intrinsic motivation can result in staff engagement, and it will motivate employees to perform better on tasks. ${ }^{11}$ Psychological empowerment focuses on the inherent motivation and not on the managerial process used to enhance employees' levels of authority. ${ }^{12}$ Spreitzer defined psychological empowerment as a motivational concept shown in four dimensions: meaning, competence, self-determination, and impact. ${ }^{13}$

\section{Objective}

Several studies have been conducted in the field of psychological empowerment, but the relationship between workload and psychological empowerment has not been clarified in them. No study was found that delineated a model of workload that could be used to identify the relationship between psychological empowerment and workload in ICUs at either the individual nurse or unit level in hospitals. The current study investigated the relationship between nurse's workload and psychological empowerment using structural equations modeling (SEM).

\section{Methods}

\subsection{Study Design}

This descriptive correlational study was conducted using structural equation modeling. SEM is a powerful multivariable analytical technique as a multi-variable regression and, more precisely, as a general linear modeling which enables researchers to test a set of regression equations simultaneously and conduct the simultaneous study of the relations among different variables. ${ }^{14}$ The importance of this technique in health science studies lies in the fact that researchers mostly study the relationship between different variables as a model or a network of relationships; therefore, based on SEM, they design the schematic of these relations in a pre-fabricated model based on their hypotheses on the relations among variables. A review of literature indicated that health services researchers consider SEM to be a proper technique for testing the complex relations among human variables and for overcoming the limitations related to traditional methods. ${ }^{15,16}$

\subsection{Setting and Sample}

This study was conducted in 17 public hospitals affiliated with Iran University of Medical Sciences (IUMS) in Tehran. The study population consisted of the nurses employed in any critical care departments including ICUs, CCUs, and NICUs in said hospitals. Exclusion criteria were less than 1 year experience of work experience in critical care departments. Although 200 samples are typically needed for SEM research, a sample size of 300 was used in this study so that it would be large enough to assess model fit based on the number of degrees of freedom and use of full information maximum likelihood (FIML) estimates for the missing data.

\subsection{Measurements/Instruments}

Two questionnaires were used to gather data: the NASA Questionnaire and the Spreitzer Psychological Empowerment Questionnaire. Hart and Staveland's NASA TLX method, used first in this study, assessed workload on five 7-point scales. Increments of high, medium, and low estimates for each point resulted in 21 gradations on the scales (Table 1).

The second questionnaire used was Spreitzer's Psychological Empowerment Questionnaire. This questionnaire was first developed conceptually and theoretically by Thomas in 1990. Then in 1995, Spreitzer used Thomas' model to measure psychological empowerment dimensions, namely competence, independence, having impact, and meaning, and then validated the dimensions. Thus, the questionnaire measures four aspects of competence, i.e. feelings of competence, self-determination, impact, and meaningfulness. Its structure is based on a seven-point Likert scale (from $1=$ strongly agree to 7 = strongly disagree) (Table 2 ).

Content validity was used to evaluate the validity of the questionnaire. Cronbach alpha was employed to assess the internal consistency (between 0.73 and 0.91). Confirmatory factor analysis was used to define the validity of the structure.

\subsection{Data Collection/Procedure}

The statistical technique of SEM defines the status of a hidden variable by computing the common variance

Table 1. Hart and Staveland's NASA Task Load Index

\begin{tabular}{lll}
\hline Title & Endpoint & Description \\
\hline Mental demand & Very low/very high & How mentally demanding was the task? \\
Physical demand & Very low/very high & How physically demanding was the task? \\
Temporal demand & Very low/very high & How hurried or rushed was the pace of the task? \\
Performance & Perfect/ failure & How successful were you in accomplishing what you were asked to do? \\
Effort & Very low/very high & How hard did you have to work to accomplish your level of performance? \\
Frustration & Very low/very high & How insecure, discouraged, irritated, stressed, and annoyed were you? \\
\hline
\end{tabular}


Table 2. Dimensions of Psychological Empowerment Questionnaire

\begin{tabular}{|c|c|c|}
\hline Description & Endpoint & Title \\
\hline $\begin{array}{l}\text { Meaningfulness is an individual's belief that his/her work is important and his/her } \\
\text { fondness for what he/she is doing. }\end{array}$ & Strongly agree/strongly disagree & Meaningfulness \\
\hline $\begin{array}{l}\text { Competence is an employee's ability to perform work activities with skill; it refers } \\
\text { to the degree to which a person can perform tasks skillfully when he/she attempts } \\
\text { them. }\end{array}$ & Strongly agree/strongly disagree & Competence \\
\hline $\begin{array}{l}\text { Self-determination is an individual's control over the manner in which work is } \\
\text { accomplished and is related to choice cognition. }\end{array}$ & Strongly agree/strongly disagree & Self-determination \\
\hline $\begin{array}{l}\text { Impact is the degree to which an individual can influence strategic, administrative, } \\
\text { and operating outcomes at work. }\end{array}$ & Strongly agree/strongly disagree & Impact \\
\hline
\end{tabular}

among the clear variables. In this study, the workload of nurses employed in critical care departments was considered as the hidden variable; personal, organizational, and occupational factors were also defined. The main steps in SEM analysis are:

1. Framing the study,

2. Controlling due to the availability of assumptions in executing the SEM,

3. Studying the fitting and trimming of the model,

4. Proper interpretation of findings.

Figure 1 shows the primary model for measuring the structural model of nurse's workload and psychological empowerment in ICUs.

In this study, 300 hospital nurses who worked in critical care departments were enrolled. Mean $( \pm S D)$ scores of workload and psychological empowerment were measured at the public hospital. Nurse's workload and psychological empowerment were measured through a self-reported survey. Scores for workload and psychological empowerment were classified into three functional categories: inadequate (score $=0-59$ ), small (score $=60$ $75)$, or adequate (score $=76-100)$.

\subsection{Data Analysis}

Descriptive statistics were computed for all variables. Differences in categorical variables such as age group, gender, and other variables were analyzed using one-way analysis of variance (ANOVA). A $P$ value $<0.005$ was used for any group of categorical variables to find statistical significance.

Confirmatory factor analyses were used to confirm the relationships between latent variables and indicator variables; SEM was used to determine the direct and indirect effects of nurse's workload on psychological empowerment.

Data analyses were performed using SPSS18, and all models were tested in LISREL 8.8.

The following indexes were used for fitting the model: chi-square statistic, GFI, AGFI, NFI, CFI, TLI, and RMSEA. The model fitting was considered desirable if the ratios exceeded $90 \% .^{17}$

\section{Results}

A total of 40 nurses refused to take part on this research for personal reasons, and 260 nurses (86\% response rate) completed the questionnaires. The majority of participants were female (55\%). The nurses' demographics, e.g., age, gender, type of critical care department, and educational level, are presented in Table 3.

This study identified the physical and mental demands related to the workload of most nurses. Nurse's competencies had the most importance, and self-determination and impact dimensions had the lowest (Table 4).

Results of ANOVAs comparing the performance levels for the five variables showed the relationship of dimensions of nurse's workload among different age groups, types of critical departments, and educational level (Table 5).

To assess the relationship between nurse's workload

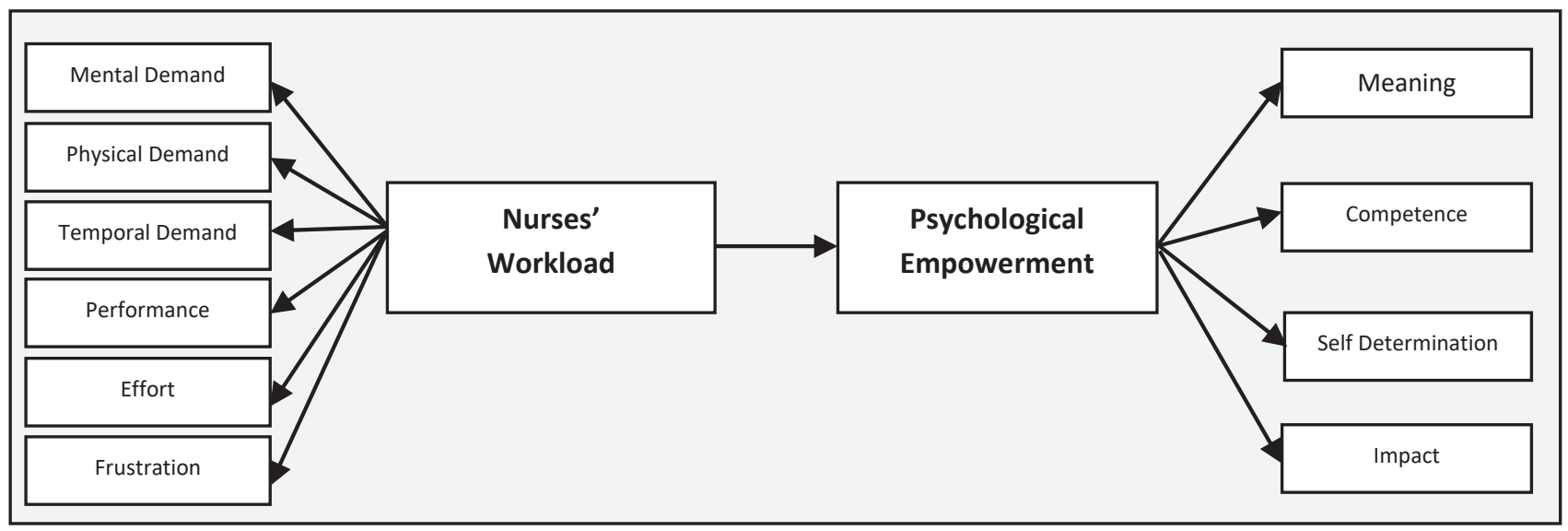

Figure 1. Measurement Model and Structural Model of Nurse's Workload and Psychological Empowerment in ICUs. 
Table 3. Descriptive Statistics

\begin{tabular}{llc}
\hline Variable & & No. $(\%)$ \\
\hline \multirow{2}{*}{ Sex } & Male & $118(45.4)$ \\
& Female & $142(54.6)$ \\
Age & $20-30$ & $51(19.6)$ \\
& $30-40$ & $70(26.9)$ \\
& $40-50$ & $124(47.7)$ \\
& Over 50 & $15(5.8)$ \\
Type of critical department & General ICU & $35(13.5)$ \\
& Burn units & $27(10.4)$ \\
& Cardiac ICU & $40(15.4)$ \\
& Open heart ICU & $40(15.4)$ \\
& Neonatal ICU & $64(24.6)$ \\
Hospital type & Surgical ICU & $54(20.8)$ \\
& Teaching & $102(39.2)$ \\
\hline
\end{tabular}

Table 4. Means and Standard Deviations for Workload and Psychological Empowerment

\begin{tabular}{lll}
\hline & Variables & Mean \pm SD \\
\hline & Mental Demand & $71.06 \pm 9.96$ \\
& Physical Demand & $74.01 \pm 12.23$ \\
Workload & Temporal Demand & $70.35 \pm 10.01$ \\
& Performance & $49.44 \pm 19.43$ \\
& Effort & $67.71 \pm 16.07$ \\
& Frustration & $59.69 \pm 20.25$ \\
Psychological & Meaning & $62.90 \pm 18.93$ \\
empowerment & Competence & $67.45 \pm 13.50$ \\
& Self-determination & $52.9 \pm 19.83$ \\
& Impact & $53.09 \pm 18.26$ \\
\hline
\end{tabular}

and psychological empowerment, SEM analysis with path methods was used to investigate the overall correlations and sub-correlations between different dimensions. Path methods analysis proposed a high direct correlation between workload and psychological empowerment. It was indicated that an increase in workload can cause the greatest psychological empowerment among nurses who work in critical care departments.

Among indicators of nursing workload, the highest correlation was performance (0.61); the highest correlation among psychological empowerment indicators was competence $(0.03)$. The overall correlation between

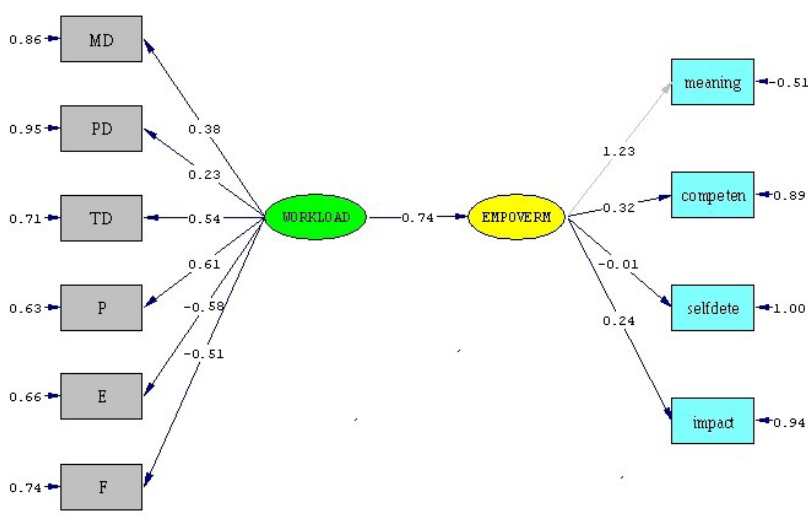

Figure 2. Model of Relationship Between Nurse's Workload and Psychological Empowerment.

nursing workload and psychological empowerment was 0.74 .

The proposed structural model fit was acceptable $\left(\chi^{2}=\right.$ $525.5, d f=89, \mathrm{RMSEA}=0.13, \mathrm{GFI}=0.91)$. The last model with significant pathways and standardized coefficients is shown in Figure 2.

\section{Discussion}

The findings of this study suggest that, among the dimensions of nurses' workload in critical care departments of hospitals, the highest ratings were related to both physical and mental demands. In the other words, the physical and mental demands in the critical wards will increase their workload.

Many reports have emphasized nurses' workload, but the workload of nurses in critical care departments must be considered with high sensitivity.

The ANOVAs showed that four dimensions of nursing workload, namely temporal demand, performance, effort, and frustration, were significantly related to age, gender, hospital type, critical care department, and education level $(P<0.005)$. The dimensions of mental demand, with the exception of gender, were significantly related to age, hospital type, critical care department, and education level $(P<0.005)$. The dimensions of physical demand, with the exception of gender and hospital type, were significantly related to age, critical care department, and education level $(P<0.005)$.

According to NAS, workload refers to the time spent by the nursing staff in providing direct care to patients within a 24 -hour period. The score for workload was higher than the scores found in national studies, which showed

Table 5. Summary of Analysis of Variances

\begin{tabular}{|c|c|c|c|c|c|c|c|c|c|c|c|c|}
\hline \multirow{2}{*}{ Variables } & \multicolumn{2}{|c|}{ Mental Demand } & \multicolumn{2}{|c|}{ Physical Demand } & \multicolumn{2}{|c|}{ Temporal Demand } & \multicolumn{2}{|c|}{ Performance } & \multicolumn{2}{|c|}{ Effort } & \multicolumn{2}{|c|}{ Frustration } \\
\hline & $\boldsymbol{F}$ & $P$ & $\boldsymbol{F}$ & $\boldsymbol{P}$ & $\boldsymbol{F}$ & $\boldsymbol{P}$ & $\boldsymbol{F}$ & $\boldsymbol{P}$ & $\boldsymbol{F}$ & $\boldsymbol{P}$ & $F$ & $\boldsymbol{P}$ \\
\hline Age group & 35.40 & $<0.001$ & 7.56 & $<0.001$ & 30.71 & $<0.001$ & 3.34 & 0.020 & 7.36 & $<0.001$ & 3.05 & 0.030 \\
\hline Gender & 0.78 & 0.376 & 3.05 & 0.082 & 268.02 & $<0.001$ & 9.53 & 0.002 & 19.04 & $<0.001$ & 15.08 & $<0.001$ \\
\hline Hospital Type & 6.65 & 0.011 & 0.00 & 0.992 & 341.94 & $<0.001$ & 16.55 & $<0.001$ & 29.53 & $<0.001$ & 15.83 & $<0.001$ \\
\hline Critical department & 37.62 & $<0.001$ & 26.17 & $<0.001$ & 89.22 & $<0.001$ & 7.39 & $<0.001$ & 6.54 & $<0.001$ & 3.51 & 0.005 \\
\hline Education level & 10.68 & 0.001 & 14.67 & $<0.001$ & 96.98 & $<0.001$ & 16.32 & $<0.001$ & 8.62 & 0.004 & 7.96 & 0.005 \\
\hline
\end{tabular}


similar or higher scores than $60 \%$. Carayon and Alvarado ${ }^{18}$ concluded that workload affects various outcomes, such as the health, safety, and quality of the working life of ICU nurses. Their results confirmed the findings of the current study.

Evidence showed that patients have an increased need for care causing a high demand for nursing in ICUs. There are numerous concerns associated with a high nursing workload. Research has shown that a nurse's workload negatively affects patient safety. ${ }^{19-21}$

A heavy nursing workload results in burnout and job dissatisfaction and is the basis for high nurse turnover. Ouyang et $\mathrm{al}^{22}$ focused on nurses working in acute care settings and identified 44 factors in three clusters (intra-, inter-, and extra-personal factors). Job satisfaction among nurses in hospital ICUs can be influenced by a combination of these factors.

The results of this study confirmed that among the four dimensions of psychological empowerment of employees (i.e. meaningfulness, competence, self-determination, and impact), competence had the highest score; it has great effects on increasing psychological empowerment.

Other studies confirmed these findings. ${ }^{23,24}$ Empowerment is an energetic side of creating encouraging work environments for nurses..$^{25,26}$ The majority of previous studies ${ }^{27,28}$ have indicated that the empowerment of employees can increase the effectiveness and satisfaction of employees and reduced job-related strain. However, this could be considered the first study so far done to measure the relationship between nursing workloads and psychological empowerment using SEM for better recognition.

Statistically significant relationships were found between psychological empowerment and nurses' workload. A SEM analysis showed that nurses' workload had a main effect on three dimensions of psychological empowerment (competence, meaning, and impact). The strong correlation between psychological empowerment and nurse's workload will lead to further psychological empowerment, and nurses' engagement in critical departments was stronger when workload was high.

Although other studies ${ }^{29,30}$ have also shown a relationship between nurse's workload and job satisfaction, it is suggested that increasing nurses' workloads in ICUs will engage nurses and allow them to face new problems they encounter in their jobs. However, it is not forgotten that increasing the workload of nurses in ICUs may reduce the quality of care provided to patients, as shown in previous studies.

SEM was used to determine direct and indirect correlates of the relationship between nursing workloads and psychological empowerment. Models fit the data well and helped explain this relationship in critical care departments. Further research is needed to determine how results compare to all nurses at hospitals.

It is recommended that factors affecting the workload of nurses in ICUs and CCUs be identified. Hospital administrators in developing employee empowerment programs should be aware of the workload in critical care.

\section{Research Highlights}

What Is Already Known?

Working in critical departments in hospitals can increase the efficiency and effectiveness of nurses, but the point that is at stake here is attention to the psychological empowerment of nurses.

\section{What This Study Adds?}

In selecting nurses for work in special sectors, their psychological abilities should be considered. Workload in hospital critical wards can increase the cognitive ability of nurses.

Although innovative, this study was not without limitations of which there are several potential ones. First of all, this was a correlation study in which the data was gathered by two self-report questionnaires, and therefore it was not possible to control the data for confounding variables. Secondly, the SEM method was used to determine the relationship between nursing workloads and psychological empowerment. A lack of precision in answering questions by the nursing staff due to the short time available to the research team could have limited the results. The third and final limitation was that the study population was confirmed by public hospitals which were educational ones. Further research needs to focus on the relationship considering the differences between private and public hospitals.

\section{Conclusion}

Increasing nurses' workloads in hospitals can improve their psychological empowerment. The increased psychological empowerment of nurses in critical care departments will increase their resilience in the face of crisis situations. Despite the impact of increased workloads on service quality in ICUs, nursing managers can use these factors to improve learning in professional nursing.

\section{Authors' Contributions}

Authors contributed to the publication of this article as follows: study concept and design, PE and ZM; analysis and interpretation of qualitative data, RZ and ZM; statistical analysis and interpretation of quantitative data, RZ and $\mathrm{ZM}$; critical revision of the manuscript, ZM.

\section{Conflict of Interest Disclosures}

The authors declare that they have no conflicts of interest.

\section{Ethical Approval}

This study was part of a project supported by IUMS (IUMS/ SHMIS-2014/727). All study participants completed the survey under the condition of anonymity.

\section{Acknowledgments}

The paper is the result of a research project funded by Iran University of Medical Sciences. The authors would like to thank the nurses for providing the necessary data and information. 


\section{References}

1. Tourangeau A, Patterson E, Rowe A, et al. Factors influencing home care nurse intention to remain employed. J Nurs Manag. 2014;22(8):1015-1026. doi:10.1111/jonm.12104.

2. Frey B, Hossle JP, Seiler Sigrist M, Cannizzaro V. Measurement of resident workload in paediatric intensive care. Swiss Med Wkly. 2013;27(143):w13844. doi:10.4414/smw.2013.13844.

3. Hoonakker $\mathrm{P}$, Carayon $\mathrm{P}$, Gurses AP, et al. Measuring workload of ICU nurses with a questionnaire survey: the NASA Task Load Index (TLX). IIE Trans Healthc Syst Eng. 2011;1(2):131-143. doi:10.1080/19488300.2011.609524.

4. Nelson J, Valentino L, lacono L, Ropollo P, Cineas N, Stuart $\mathrm{S}$. Measuring workload of nurses on a neurosurgical care unit. J Neurosci Nurs. 2015;47(3):E9-E19. doi:10.1097/ INN.0000000000000136

5. Kowitlawakul Y, Leong BS, Lua A, Aroos R, Wong JJ, Koh N, et al. Observation of handover process in an intensive care unit (ICU): barriers and quality improvement strategy. Int J Qual Health Care. 2015;27(2):99-104. doi:10.1093/intqhc/mzv002.

6. Danque CT, Serafica R, Lane SH, Hodge MA. Incivility in the hospital environment: the nurse educator-staff nurse relationship. J Nurses Prof Dev. 2014;30(4):185-189. doi:10.1097/NND.0000000000000059.

7. Grafen M, Mackenzie FC. Development and early application of the Scottish Community Nursing Workload Measurement Tool. Br J Community Nurs. 2015;20(2):89-92. doi:10.12968/ bjen.2015.20.2.89

8. Roch G, Dubois CA, Clarke SP. Organizational climate and hospital nurses' caring practices: a mixed methods study. Res Nurs Health. 2014;37(3):229-240. doi:10.1002/nur.21596.

9. Hoonakker P, Carayon P, Gurses A, et al. Measuring workload of icu nurses with a questionnaire survey: The NASA Task Load Index (TLX). IIE Trans Healthc Syst Eng. 2011;1(2):131-143. doi:10.1080/19488300.2011.609524.

10. Havaei F, Dahinten VS, MacPhee M. Psychological competence: the key to leader empowering behaviors. J Nurs Adm. 2014;44(5):276-283. doi:10.1097/NNA.0000000000000067.

11. Wang S, Liu Y. Impact of professional nursing practice environment and psychological empowerment on nurses' work engagement: test of structural equation modelling. J Nurs Manag. 2015;23(3):287-296. doi:10.1111/jonm.12124.

12. Firth BM, Chen G, Kirkman BL, Kim K. Newcomers abroad: Expatriate adaptation during early phases of international assignments. Acad Manage J. 2014;57(1):280-300. doi:10.5465/amj.2011.0574.

13. Spreitzer GM. Psychological empowerment in the workplace: Dimensions, measurement, and validation. Acad Manage J. 1995;38(5):1442-1465. doi:10.2307/256865

14. MacCallum RC, Austin JT. Applications of structural equation modeling in psychological research. Annu Rev Psychol. 2000;51:201-226. doi:10.1146/annurev.psych.51.1.201.

15. Guo J, Wang T-F, Liao J, Huang C. Efficacy of the theory of planned behavior in predicting breastfeeding: meta-analysis and structural equation modeling. Appl Nurs Res. 2016;29:3742. doi:10.1016/j.apnr.2015.03.016.

16. Spence Laschinger HK, Fida R. Linking nurses' perceptions of patient care quality to job satisfaction: the role of authentic leadership and empowering professional practice environments. J Nurs Adm. 2015;45(5):276-283. doi:10.1097/ NNA.0000000000000198.

17. Schreiber JB. Core reporting practices in structural equation modeling. Res Social Adm Pharm. 2008;4(2):83-97. doi:10.1016/j.sapharm.2007.04.003.

18. Carayon P, Alvarado CJ. Workload and patient safety among critical care nurses. Crit Care Nurs Clin North Am. 2007;19(2):121-129. doi:10.1016/j.ccell.2007.02.001.

19. Crane PW, Zhou Y, Sun Y, Lin L, Schneider SM. Entropy: a conceptual approach to measuring situation-level workload within emergency care and its relationship to emergency department crowding. J Emerg Med. 2014;46(4):551-559. doi:10.1016/j.jemermed.2013.08.113.

20. Lin SH, Liao WC, Chen MY, Fan JY. The impact of shift work on nurses' job stress, sleep quality and self perceived health status. J Nurs Manag. 2014;22(5):604-12. doi:10.1111/jonm.12020.

21. Surani S, Hesselbacher S, Guntupalli B, Surani S, Subramanian S. Sleep quality and vigilance differ among inpatient nurses based on the unit setting and shift worked. J Patient Saf. 2015;11(4):215-220. doi:10.1097/pts.0000000000000089.

22. Ouyang YQ, Zhou WB, Qu H. The impact of psychological empowerment and organizational commitment on Chinese nurses' job satisfaction. Contemp Nurs. 2015;50(1):80-91. doi: 10.1080/10376178.2015.1010253

23. Read EA, Laschinger HK. The influence of authentic leadership and empowerment on nurses' relational social capital, mental health and job satisfaction over the first year of practice. J Adv Nurs. 2015;71(7):1611-1623. doi:10.1111/jan.12625.

24. Slatyer S, Williams AM, Michael R. Seeking empowerment to comfort patients in severe pain: a grounded theory study of the nurse's perspective. Int J Nurs Stud. 2015;52(1):229-239. doi:10.1016/j.ijnurstu.2014.06.010.

25. Van Bogaert P, Peremans L, Diltour N, et al. Staff Nurses' Perceptions and Experiences about Structural Empowerment: A Qualitative Phenomenological Study. PLoS One. 2016;11(4):e0152654. doi:10.1371/journal.pone.0152654.

26. Mozaffari N, Peyrovi H, Nayeri ND. The social well-being of nurses shows a thirst for a holistic support: a qualitative study. Int J Qual Stud Health Well-being. 2015;10:27749. doi:10.3402/qhw.v10.27749.

27. Kang H. Geriatric hospital nurses' perceived barriers to research utilization and empowerment. Asian Nurs Res (Korean Soc Nurs Sci). 2015;9(1):65-72. doi:10.1016/j.anr.2014.11.005.

28. Kennedy S, Hardiker N, Staniland K. Empowerment an essential ingredient in the clinical environment: A review of the literature. Nurse Educ Today. 2015;35(3):487-492. doi:10.1016/j.nedt.2014.11.014.

29. Sansoni J, De Caro W, Marucci AR, Sorrentino M, Mayner L, Lancia L. Nurses' Job satisfaction: an Italian study. Ann Ig. 2016;28(1):58-69. doi:10.7416/ai.2016.2085.

30. Atefi N, Abdullah KL, Wong LP, Mazlom R. Factors influencing registered nurses perception of their overall job satisfaction: a qualitative study. Int Nurs Rev. 2014;61(3):352-360. doi:10.1111/inr.12112. 